\title{
A case of ovarian fibroma masquerading as a uterine fibroid
}

\author{
Raksha K. Shetty*, Sadhana K. Desai, Prema M. Kania, Shruti K. Chandak
} Department of Obstetrics and Gynaecology, Bombay Hospital Institute of Medical Sciences and Research, Mumbai,
Maharashtra, India

Received: 12 October 2016

Accepted: 07 November 2016

*Correspondence:

Dr. Raksha K. Shetty,

E-mail: rkshetty.gs@gmail.com

Copyright: () the author(s), publisher and licensee Medip Academy. This is an open-access article distributed under the terms of the Creative Commons Attribution Non-Commercial License, which permits unrestricted non-commercial use, distribution, and reproduction in any medium, provided the original work is properly cited.

\begin{abstract}
A case of a 37-year old patient who presented with a pelvic mass, recurrent urinary tract infection, urinary hesitancy and elevated serum CA-125 levels. A diagnosis of a large, posterior wall uterine fibroid was made on the basis of clinical examination and radiological imaging and abdominal myomectomy was planned. Intraoperative findings were a large left ovarian mass and multiple small uterine fibroids. The ovarian mass was removed and its histopathological examination findings were suggestive of an ovarian fibroma. This article highlights the unique clinical and radiological presentation of an adnexal mass as a fibroid and the non-specificity of CA-125 as a marker of ovarian malignancy.
\end{abstract}

Keywords: CA-125, Ovarian fibroma, Radiographic features, Spindle cell tumour

\section{INTRODUCTION}

An ovarian fibroma is a benign sex-cord stromal tumour. Ovarian fibromas represent $4 \%$ of all ovarian neoplasms. ${ }^{1}$ Mostly occur in peri- and post-menopausal age groups, median age being 52 years. ${ }^{1}$ They tend to be asymptomatic. If symptoms are present, the most common one is abdominal pain. ${ }^{1}$ On gross pathology, they are firm and white or tan. The cut surface is greywhite and homogeneous with a whorled pattern and occasional areas of calcification. On microscopic examination, there are intersecting bundles of spindle cells producing collagen. There may be thecomatous areas (fibrothecoma). The presence of an ovarian fibroma can cause ovarian torsion in some cases. Ovarian fibroma is almost always benign in nature. It may be associated with ascites and hydrothorax, known as Meigs' syndrome. We report a case of an ovarian fibroma with unique clinical and radiological presentation and an elevated serum CA-125 level.

\section{CASE REPORT}

A 37-year old patient, married since 10 years, P1L1, presented with a pelvic mass and a history of recurrent urinary tract infection since 1 month. Her menstrual cycles were regular, 28 day cycles, menses lasting 3-4 days, with normal flow and painless. There was no history of loss of weight or appetite or bowel disturbances. There was no family history of any malignancy. She had a previous normal delivery 9 years ago. Her general physical examination was unremarkable. Per abdomen examination revealed a firm mass in the midline, arising from the pelvis, corresponding to a 20 weeks gravid uterus. Pelvic examination revealed a firm mass, not separable from the uterus and with fullness in the posterior fornix and pouch of Douglas.

Routine laboratory tests were within normal limits.

Serum CA-125 level was 166.6U/ml. 
Chest X-Ray and ECG findings were within normal limits.

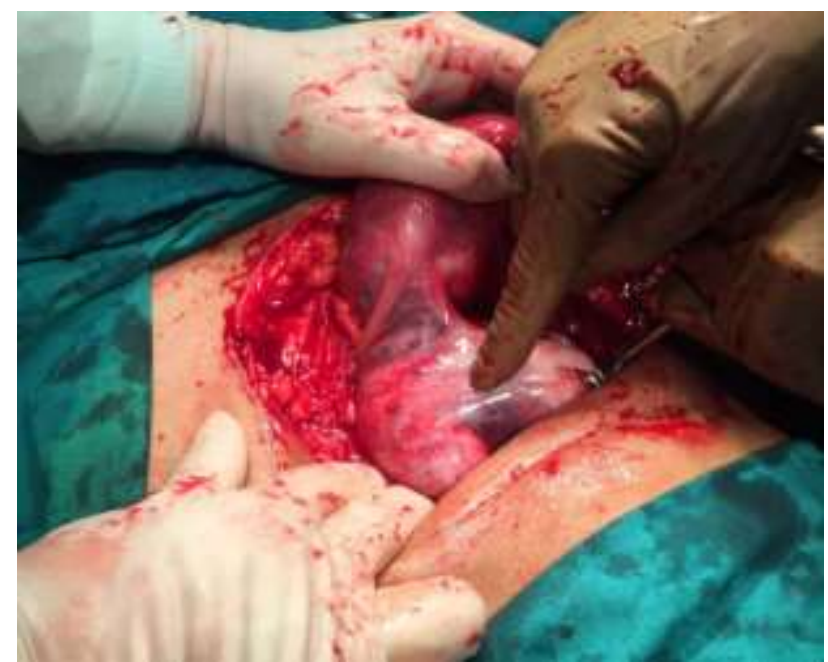

Figure 1: The left ovarian fibroma in situ.

Ultrasonography of abdomen and pelvis showed a large subserosal fibroid, $15 \mathrm{~cm} \times 10 \mathrm{~cm}$ in size, arising from the posterior uterine wall, with multiple small intramural fibroids. Bilateral ovaries and rest of pelvis and abdomen were normal on ultrasound.

CT scan of abdomen and pelvis showed a large posterior wall uterine fibroid, $10.4 \mathrm{~cm} \times 10.3 \mathrm{~cm}$ in size; the left ovary was not separately visualized. Right ovary and rest of pelvis and abdomen were normal on CT scan.

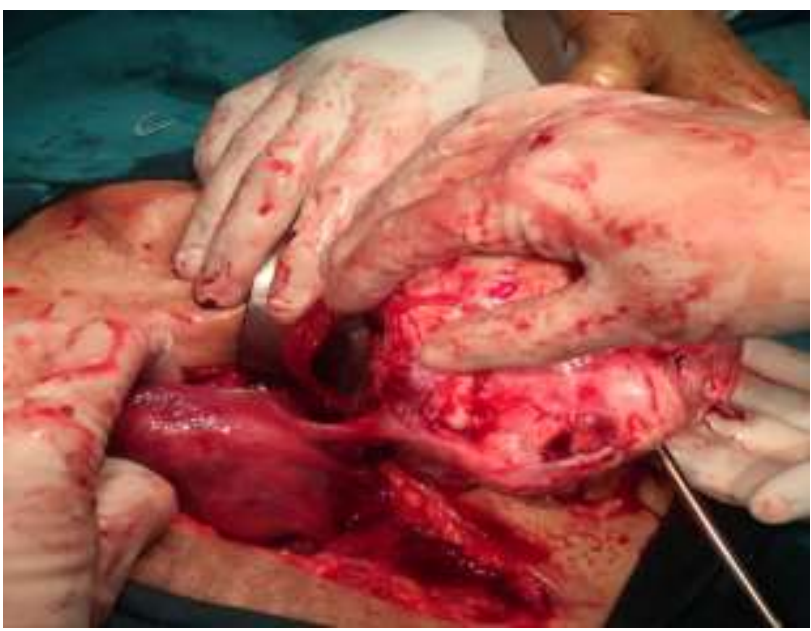

Figure 2: Exteriorising the left ovarian mass.

Based on the clinical presentation, examination findings and investigations, a provisional diagnosis of a large posterior wall uterine fibroid was made. Written, informed, valid consent taken and patient posted for exploratory laparotomy and myomectomy.

Abdomen was opened through a Pfannensteil incision. Intra-operative findings were as follows: a. A left ovarian mass, $14 \mathrm{~cm} \times 10 \mathrm{~cm} \times 9 \mathrm{~cm}$ in size, with a smooth, white, bossellated appearance, abutting the posterior surface of the uterus.

b. Left fallopian tube was normal.

c. Right ovary and right fallopian tube were normal.

d. Uterus was normal in size with 2 fundal, intramural fibroids, $4 \times 3.5 \times 2.5 \mathrm{cms}$ and $2 \times 2 \mathrm{cms}$ in size and 2 small, $1 \times 1 \mathrm{~cm}$ sized posterior wall intramural fibroids which were later removed by dissection and enucleation and histopathology showed leiomyomata.

Exploration of rest of abdominal cavity revealed no abnormality.

The left ovarian mass was removed and sent for frozen section examination which revealed a benign spindle cell tumour, differential diagnoses being ovarian fibroma and ovarian leiomyoma.

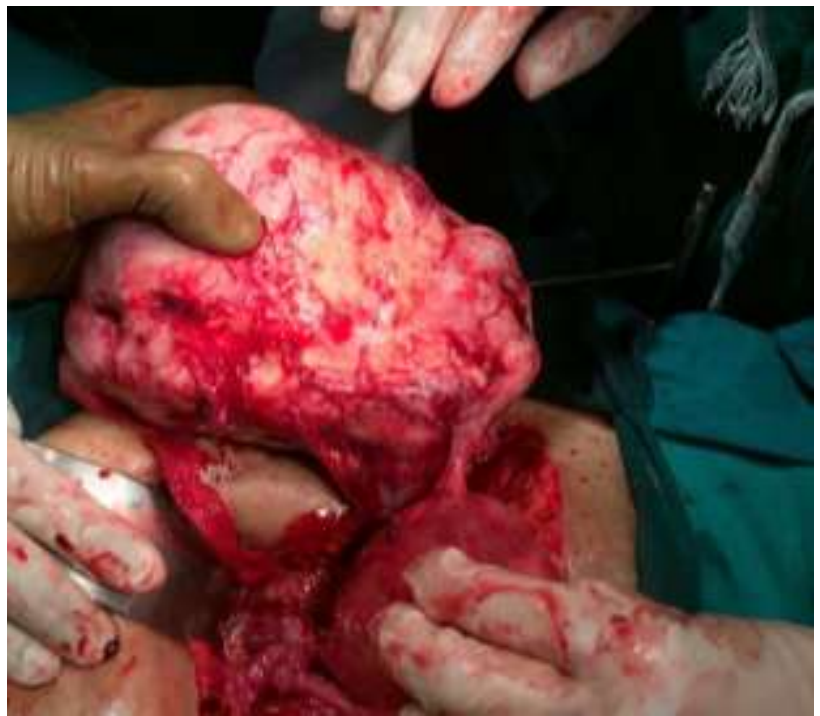

Figure 3: Left ovarian fibroma exteriorised.

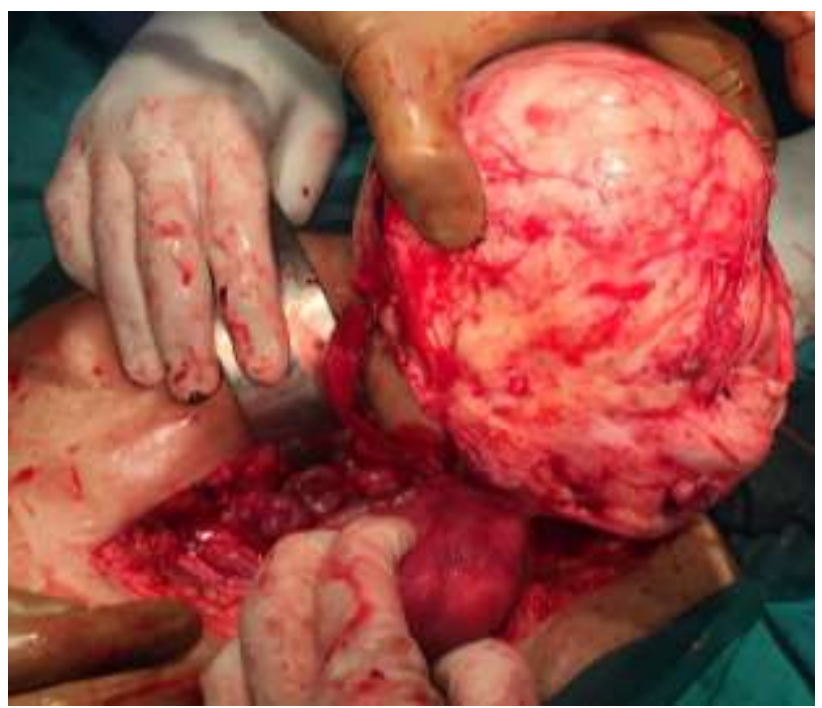

Figure 4: Fibroma removed. 
Grossly, the left ovarian mass, 14x10x9 cm, weighed 800 gms. External surface was smooth; bosselated with a raw area (capsular tear).Cut surface was whitish and whorled.

Final histopathology report of the mass was suggestive of an ovarian fibroma. There was no evidence of malignancy.

The surgery and postoperative period were uneventful. Patient was comfortable at discharge on postoperative day 4.

\section{DISCUSSION}

Ovarian fibromas are stromal tumours composed of spindle, oval or round cells producing collagen. ${ }^{[2]}$ Fibromas are usually solid, slightly lobulated, encapsulated, grey-white masses covered by a glistening, intact ovarian serosa and mostly unilateral. ${ }^{3}$ Fibromas occur at all ages, most frequently during middle age, with an average age of 48 years. ${ }^{4}$ Ovarian fibromas are almost always benign. Very rarely, fibromas without any atypical features are associated with peritoneal implants. ${ }^{5}$ Surgical removal of these solid ovarian tumours is recommended because of the low probability of malignancy. ${ }^{6}$

Ovarian lesions composed of spindle cells comprise a heterogeneous group; most are neoplastic but several non-neoplastic conditions are also composed of spindle cells. The majority of ovarian spindle cell lesions fall into the broad category of fibromatous neoplasms whereas others in the sex cord-stromal group may also be composed of spindle cells, including the comas, granulosa and Sertoli-Leydig cell tumors and rarer neoplasms, such as sclerosing stromal tumour and signetring stromal tumor. In the recent past there have been several major contributions on various aspects of ovarian spindle cell lesions, including cellular and mitotically active cellular fibromatous lesions, smooth muscle neoplasms, and metastatic gastrointestinal stromal tumours. Other mesenchymal or epithelial tumors and mixed epithelial and mesenchymal neoplasms may also enter into the differential diagnosis of an ovarian spindle cell lesion. Several non-neoplastic lesions may be composed of spindle cells, including massive oedema, ovarian fibromatosis, stromal hyperplasia, and stromal hyperthecosis. Morphology remains the mainstay in diagnosis but immunohistochemistry may be invaluable in certain circumstances, one example being the identification of a metastatic gastrointestinal stromal tumor within the ovary. ${ }^{7}$

CA-125 antigen is a glycoprotein with a high molecular weight and is recognized by a monoclonal antibody (OC125). It is expressed in the amnion and embryonic coelomic epithelium. ${ }^{8}$ The antigen can also appear in many adult tissues such as the epithelium of the fallopian tubes, endometrium, endocervix, and ovaries. ${ }^{9}$ In addition, it is found in mesothelial cells of the pleura, pericardium and peritoneum. Therefore, some normal body tissues can produce a certain and low level of circulatory or serum CA-125. This tumour marker is found elevated during menstruation or pregnancy and in some benign conditions such as endometriosis, leiomyomas, peritonitis or cirrhosis, particularly with ascites. ${ }^{10,11}$ It is also increased in vascular invasion, tissue destruction and inflammation associated with malignant disease. In a series by O'Connell et al, the predictive value of a CA-125 level greater than $35 \mathrm{U} / \mathrm{ml}$ was $60 \%$ for ovarian cancer and $84 \%$ for some type of malignancy. ${ }^{12}$ The authors also reported three patients with ovarian fibroma and elevated serum CA-125 levels (above $35 \mathrm{U} / \mathrm{ml}$ ) in their series. No details were given whether these patients also had Meigs' syndrome.

CA-125 as a tumour marker of ovarian carcinoma has been suggested as a valuable tool to assist in distinguishing between benign and malignant neoplasms. Unfortunately, it has not proved to be a reliable predictor of ovarian cancer as normal values do not exclude the presence of carcinoma and elevated levels can be associated with a benign diagnosis. ${ }^{13}$

Spinelli, et al, also reported a case of benign ovarian fibroma with elevated CA-125 levels. ${ }^{14}$

Although ovarian fibroma is diagnosed in $2-5 \%$ of all surgically removed ovarian tumours, Meigs' syndrome is observed in approximately $1 \%$ of cases only. ${ }^{15,16}$ Ascites is present in $10-15 \%$ of patients with ovarian fibroma, and pleural effusion is present in $1 \%$,especially in cases showing large lesions. ${ }^{17,18}$ However, most patients with ovarian fibromas remain asymptomatic, with the tumor often progressing to a large pelvic mass. ${ }^{18}$ The immunohistochemical study for CA-125 suggested that serum elevation of CA-125 antigen in patients with Meigs' syndrome is caused by mesothelial expression of CA-125 rather than by fibroma. ${ }^{19,20}$ The mechanism is unclear, but a mechanical irritation from a large tumour, or an increase in intraperitoneal pressure from a large volume of ascites might be primary factors in this process.

\section{Radiographic features}

Ultrasound: On ultrasound, fibromas most commonly manifest as solid, hypoechoic masses with ultrasound beam attenuation. ${ }^{21}$ As such, they may appear similar to a pedunculated subserosal uterine fibroid. However, the sonographic appearance can be variable and some tumours can rarely have cystic components.

Computed Tomography (CT): Fibromas usually manifest as diffuse, slightly hypoattenuating masses with poor, very slow contrast enhancement. Calcification and bilaterality are both uncommon.

\section{Magnetic Resonance Imaging (MRI): Signal} characteristics include: 
T1: fibromas usually demonstrate homogeneous low signal intensity

T2: fibromas appear as well-circumscribed masses with low signal intensity may contain scattered hyperintense areas representing oedema or cystic degeneration a band of T2 hypointensity separating the tumour from the uterus on all imaging planes is also considered a characteristic feature.

T1 $C+(G d): \quad$ Usually shows heterogenous enhancement.

In a study to assess the accuracy of MRI, particularly, dynamic MRI, in distinguishing ovarian fibromas from subserous uterine leiomyomas, it was found that dynamic contrast-enhanced- MRI (DCE-MRI) can distinguish ovarian fibromas from uterine leiomyomas and should be used if sonography fails to show the origin of a pelvic mass. $^{22}$

In clinical practice, an ovarian tumour may be misdiagnosed as a complex, degenerated subserosal myoma because of the lack of clarity in the gray-scale ultrasound findings. In addition, a mildly elevated level of serum CA-125 is common in patients with uterine diseases. ${ }^{23}$ The differentiation of ovarian fibroma from malignant ovarian tumour based on abdominal computed tomography is also difficult. ${ }^{23}$ Furthermore, the benign sclerosing stromal tumour exhibits clinical features that are similar to those of ovarian fibroma in Meigs' syndrome, including elevated serum CA-125. ${ }^{23}$ As occurred in our case, ovarian fibroma is often difficult to diagnose and the tumour is not often diagnosed accurately until the time of surgery. It has been reported that $34 \%$ of ovarian fibromas were misdiagnosed preoperatively as uterine myoma. ${ }^{6}$ Thus, surgery and histological confirmation of the preoperative diagnosis are mandatory, especially in premenopausal patients. The treatment consists of surgical resection of the tumour which is associated with very low recurrence rates and laparoscopic surgery can be an effective and safe alternative approach. Laparoscopic assisted vaginal hysterectomy can also be done, the tumour being removed in an endobag. ${ }^{24}$

Associations: Ovarian fibromas are associated with naevoid basal cell carcinoma syndrome (Gorlin syndrome) (24\% cases) and Meigs' syndrome (triad of ascites, hydrothorax and ovarian fibroma). ${ }^{25}$

\section{CONCLUSION}

Ovarian fibromas are uncommon but are the most common benign solid tumours of the ovary. They constitute about $4 \%$ of all ovarian tumours. This tumor is often misdiagnosed as a uterine myoma in ultrasonographic findings and is sometimes mistaken for a malignant tumor of the ovary, because of its solid nature, increased tumour marker levels, and accompanying ascites. However, ovarian fibromas are benign and can be treated completely by surgical removal, and laparoscopic surgery can be an effective and safe alternative approach.This case report depicts the unique presentation of an ovarian fibroma and the nonspecificity of CA-125 as a marker of ovarian malignancy. It beckons us to re-evaluate the presumption that thorough clinical examinations supported by laboratory investigations and imaging modalities are fool-proof in themselves. The role of a histopathological diagnosis should not be underestimated even in cases with a strong suspicion of malignancy.

\section{ACKNOWLEDGEMENT}

The authors would like to thank the patient in this case report and the Department of Obstetrics and Gynaecology, Bombay Hospital Institute of Medical Sciences and Research, Mumbai, Maharashtra, India.

Funding: No funding sources

Conflict of interest: None declared

Ethical approval: Not required

\section{REFERENCES}

1. Yen P, Khong K, Lamba R, Corwin MT, Gerscovich EO. Ovarian fibromas and fibrothecomas: Sonographic correlation with computed tomography and magnetic resonance imaging: A 5-year singleinstitution experience. Journal of ultrasound in medicine: official journal of the American Institute of Ultrasound in Medicine. 2013;32(1):13-18.

2. Tavassoli FA, Mooney E, Gersell DJ, McCluggage WG, Konishi I, Fujii S, et al. Sex-Cord Stromal Tumors. In: World Health Organisation Classification of Tumors. Pathology and Genetics of Tumors of the Breast and Female Genital Organs. Lyon, France: IARC Press; 2003:149.51.

3. Crum CP. The Female Genital Tract. In: Kumar V, Abbas AK, Fausto N, editors. Robbins and Cotran Pathologic basis of disease. $7^{\text {th }}$ ed. Philadelphia: WB Saunders Company; 2004:1059.117.

4. Dockerty MB, Masson JC. Ovarian fibroma-A clinical and pathological study of two hundred and eighty three cases. Am J Obstet Gynecol 1944;47:741-52.

5. Young RH, Scully RE. Sex Cord-Stromal, Steroid Cell and other ovarian tumors with Endocrine, Paraendocrine and Paraneoplastic manifestation. In: Kurman RJ, editors. Blausteins Pathology of the Female Genital Tract. 5th ed. India: Springer Private Limited; 2004:923.5.

6. Leung SW, Yuen PM. Ovarian fibroma: A review on the clinical characteristics, diagnostic difficulties and management option in 23 cases. Gynecol Obstet Invest. 2006;62:1.6.

7. Irving JA, McCluggage WG. Ovarian spindle cell lesions: a review with emphasis on recent 
developments and differential diagnosis. Adv Anat Pathol. 2007;14(5):305-19.

8. Bast RC, Feeney M, Lazarus H, Nadler LM, Colvin RB, Knapp RC. Reactivity of a monoclonal antibody with human ovarian carcinoma. J Clin Invest. 1981;68:1331-7.

9. Kabawat SE, Bast RC, Bhan AK, Welch WR, Knapp RC, Colvin RB. Tissue distribution of a coelomicepithelium-related antigen recognized by the monoclonal antibody OC125. Int J Gynecol Pathol. 1983;2:275-85.

10. Jacobs I, Bast RC. The CA 125 tumour-associated antigen: a review of the literature. Hum Reprod. 1989;4:1-12.

11. Kudlacek S, Schieder K, Kölbl H. Use of CA 125 monoclonal antibody to monitor patients with ovarian cancer. Gynecol Oncol. 1989;35:323-9.

12. O'Connell GJ, Ryan E, Murphy KJ, Prefontaine M. Predictive value of CA 125 for ovarian carcinoma in patients presenting with pelvic masses. Obstet Gynecol. 1987;70:930-2.

13. Walker JL, Manetta A, Mannel RS, Shu-Yuan L. Cellular fibroma masquerading as ovarian carcinoma. Obstet Gynecol. 1990;76:530.

14. Spinelli C, Gadducci A, Bonadio AG, Berti P, Micolli P. Benign ovarian fibroma associated with free peritoneal fluid and elevated serum CA-125 levels. Minnerva Ginecol. 1999;51:403-7.

15. Scully RE. Ovarian tumors: a review. Am J Pathol. 1977;87:686-720.

16. Young RH, Scully RE. Ovarian sex cord-stromal tumors. Problems in differential diagnosis. Pathol Annu. 1988;23:237-96.

17. Liou JH, Su TC, Hsu JC. Meigs' syndrome with elevated serum cancer antigen 125 levels in a case of ovarian sclerosing stromal tumor: a case report. Taiwan J Obstet Gynecol 2011;50:196e200.
18. Chan CY, Chan SM, Liauw L. A large mass in a young girl. Br J Radiol. 2000;73:913-4.

19. Lin JY, Angel C, Sickel JZ. Meigs syndrome with elevated serum CA 125 . Obstet Gynecol. 1992;80:563-6.

20. Timmerman D, Moerman P, Vergote I. Meigs'syndrome with elevated serum CA 125 levels: two case reports and review of the literature. Gynecol Oncol. 1995;59:405-8.

21. Ovarian fibroma | Radiology Reference Article |Radiopaedia.org Available at http://www.radiopaedia.org

22. Thomassin-Naggara I, Daraï E, Nassar-Slaba, Jinane C, Annie M, Claude B, et al. Value of Dynamic Enhanced Magnetic Resonance Imaging for Distinguishing Between Ovarian Fibroma and Subserous Uterine Leiomyoma. Journal of Computer Assisted Tomography. 2007;31(2):236-42.

23. Wing-Yuk C, Chuan-Yaw C, Chiou-Chung Y, PiHua C. Correlation of ovarian fibroma with elevated serum CA-125. Taiwanese $\mathrm{J}$ of Obs and Gyn. 2014;53:95-6.

24. Son CE, Choi JS, Lee JH, Jeon SW, Hong JH, Bae JW. Laparoscopic Surgical Management and Clinical Characteristics of Ovarian Fibromas.JSLS : Journal of the Society of Laparoendoscopic Surgeons. 2011;15(1):16-20.

25. Ladusans EJ, SRimmer LD Burnell N, Thakker PA Farndon. Complications of the naevoid basal cell carcinoma syndrome: results of a population based study.Journal of Medical Genetics. J Med Genet. 1993;30:460-4.

Cite this article as: Shetty RK, Desai SK, Kania PM, Chandak SK. A case of ovarian fibroma masquerading as a uterine fibroid. Int J Reprod Contracept Obstet Gynecol 2016;5:4514-8. 